\title{
A case of advanced atrioventricular block after gynecological surgery
}

\author{
Takuzou Kitazawa, Mitsuru Ida* (i) and Masahiko Kawaguchi
}

To the Editor,

Advanced atrioventricular block (AVB) after noncardiac surgery is rare, but occasionally leads to serious complications such as syncope. After the onset of AVB, the causes are investigated and treatment is selected according to the symptoms [1]. We report a case of advanced $A V B$ in the patient without any comorbidities after gynecological surgery that may have been triggered by postoperative nausea.

Open uterine myomectomy was planned for a 39year-old healthy woman. Her electrocardiographic findings were normal range and there was no history of loss of consciousness before surgery. After the uneventful anesthesia induction, her trachea was intubated. Then, a mixture of $0.375 \%$ ropivacaine (total dose $40 \mathrm{~mL}$ ) was injected bilaterally into the fascial plane with ultrasound. Intraoperatively, general anesthesia was maintained with propofol, fentanyl $(250 \mathrm{mcg})$, remifentanil, and rocuronium and no antiemetics were administrated. After the uneventful procedure, the trachea was extubated following administration of sugammadex, and the patient was transferred to the general ward with an Aldrete score of 10 [2]. On postoperative day $1,17 \mathrm{~h}$ and $14 \mathrm{~min}$ after surgery, she first complained of nausea and suddenly lost consciousness following oculogyric crisis and rigidity of her upper extremities. She then spontaneously regained consciousness in approximately 25 $\mathrm{s}$ (Fig. 1). The same loss of consciousness following nausea occurred three times within $2 \mathrm{~h}$ after she first lost consciousness. A consulted cardiologist made a diagnosis of advanced AVB. Her blood sample, echocardiography, and electrocardiogram ruled out electrolyte abnormalities and myocardial ischemia. Then, with the administration of antiemetic drug, a temporary transvenous cardiac pacing leads were placed. After that, the patient followed an uneventful course without nausea and developing advanced AVB and was discharged from our hospital with removal of her temporary pacing lead on postoperative day 10 .

It has been reported that nausea and vomiting can stimulate the vagal nerve to induce bradycardia and AVB [3]. Recently, however, the vagal score was developed to determine the involvement of the vagal nerve in AVB using electrocardiogram waveforms with a total score $\geq 3$ strongly suggesting a vagal mediated mechanism [4]. In our case, following four items were positive with the total score of 4 ; no AVB or intraventricular conduction disturbance on the baseline electrocardiogram, PR prolongation immediately before paroxysmal AVB, sinus slowing immediately before paroxysmal AVB, resumption of atrioventricular conduction with PP shortening. Additionally, the fact that multiple advanced AVBs following nausea perhaps indicate that the vagal nerve was stimulated by nausea [3]. Furthermore, temporary pacing lead was placed because of her multiple loss of consciousness. In order to prevent postoperative nausea and vomiting, general anesthesia was maintained with propofol; however, prophylactic adminis-

\footnotetext{
* Correspondence: nwnh0131@yahoo.co.jp

Department of Anesthesiology, Nara Medical University, 840 Shijo-cho, Kashihara, Nara 634-8522, Japan
} 


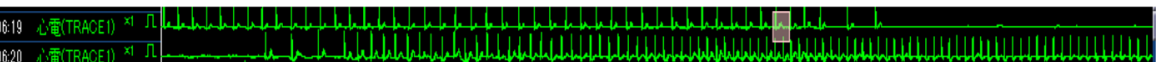

06:19:37

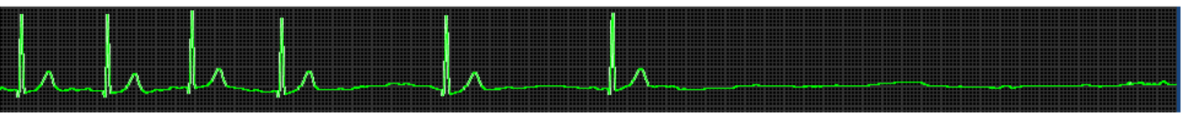

06:20:03

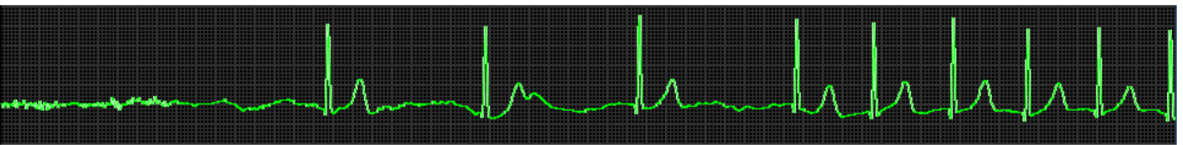

Fig. 1 Electrocardiogram recorded in the ward 17 hours and 14 minutes after surgery. Trend recording during the first episode of bradycardia (top), at the onset of bradycardia and cardiac arrest (middle) and spontaneous recovery approximately in $23 \mathrm{~s}$ (bottom)

tration of anti-emetics might reduce the incidence and the severity of postoperative nausea [5]. Postoperative advanced AVB occurs in non-cardiac surgery; however, early detection of the cause can help explain the mechanism of advanced AVB to patient. Furthermore, because postoperative nausea and vomiting may have caused advanced AVB by stimulating the vagal nerve, more careful management strategy to prevent postoperative nausea and vomiting may have been necessary in patients at high risk for postoperative nausea and vomiting.

\section{Acknowledgements}

Not applicable

Authors' contributions

M.I. wrote the paper. All authors read and approved the final manuscript.

\section{Funding}

The authors received no financial support for publication of this article.

Availability of data and materials

Not applicable

Ethics approval and consent to participate

Not applicable

\section{Consent for publication}

Written informed consent was obtained by the patient.

\section{Competing interests}

The authors declare that they have no competing interests.

Received: 12 September 2020 Revised: 29 September 2020 Accepted: 1 October 2020 Published online: 09 October 2020

\section{References}

1. Members WC, Kusumoto FM, Schoenfeld MH, Barrett C, Edgerton JR, Ellenbogen KA, Gold MR, Goldschlager NF, Hamilton RM, Joglar JA, Kim RJ, Lee R, Marine JE, McLeod CJ, Oken KR, Patton KK, Pellegrini CN, Selzman KA, Thompson A, Varosy PD. 2018 ACC/AHA/HRS guideline on the evaluation and management of patients with bradycardia and cardiac conduction delay: Executive summary: A Report of the American College of Cardiology/ American Heart Association Task Force on Clinical Practice Guidelines, and the Heart Rhythm Society. Heart Rhythm. 2019;16:e227-79.
2. Aldrete JA, Kroulik D. A postanesthetic recovery score. Anesth Analg. 1970; 49:924-34.

3. Mehta D, Saverymuttu SH, Camm AJ. Recurrent paroxysmal complete heart block induced by vomiting. Chest. 1988;94:433-5.

4. Komatsu S, Sumiyoshi M, Miura S, Kimura Y, Shiozawa T, Hirano K, Odagiri F, Tabuchi H, Hayashi H, Sekita G, Tokano T, Nakazato Y, Daida H. A proposal of clinical ECG index "vagal score" for determining the mechanism of paroxysmal atrioventricular block. J Arrhythm. 2017;33:208-13.

5. Gan TJ, Diemunsch P, Habib AS, Kovac A, Kranke P, Meyer TA, Watcha M, Chung F, Angus S, Apfel CC, Bergese SD, Candiotti KA, Chan MT, Davis PJ, Hooper VD, Lagoo-Deenadayalan S, Myles P, Nezat G, Philip BK, Tramèr MR, Society for Ambulatory Anesthesia, et al. Anesth Analg. 2014;118:85-113.

\section{Publisher's Note}

Springer Nature remains neutral with regard to jurisdictional claims in published maps and institutional affiliations.

\section{Submit your manuscript to a SpringerOpen ${ }^{\circ}$ journal and benefit from:}

- Convenient online submission

- Rigorous peer review

- Open access: articles freely available online

- High visibility within the field

- Retaining the copyright to your article

Submit your next manuscript at $\boldsymbol{\nabla}$ springeropen.com 